\title{
Perspectivas em Reciclagem, Caracterização e Processamento - Uma Contribuição das Comissões Técnicas da ABPol
}

Nos oito anos consecutivos de realização do Seminário das Comissões Técnicas foram das mais significativas para a comunidade as discussões sobre os três temas que norteiam as reuniões: 'Reciclagem de Plástico', 'Reologia e Processamento de Polímeros'e 'Identificação e Caracterização de Polímeros'. Academia, indústria, grandes, pequenos, todos se unem para aprender e trocar experiências dentro de um grupo numericamente constante, fechado em uma centena de participantes. $O$ público das reuniões regulares de cada Comissão tem crescido significativamente nos últimos meses e também a interação entre os diferentes grupos, evidência de que as pessoas estão ampliando suas áreas de interesse. Polímeros, Ciência e Tecnologia traz, nesta edição, os destaques do $8^{\circ}$ Seminário das Comissões Técnicas, realizado no auditório do IPT, em São Paulo, nos dias 3 e 4 de junho último.

Um dia e meio foi o necessário para a rodada de palestras e debates organizados por Sebastião V. Canevarolo, Hélio Wiebeck, Júlio Harada e Selma M. L. Guedes, respectivamente diretor da ABPol e coordenadores das Comissões Técnicas de Reciclagem de Plástico, Reologia e Processamento de Polímeros e Identificação e Caracterização de Polímeros. Os leitores terão um resumo dos pontos mais importantes discutidos durante as mesasredondas que ocorreram ao final de cada período, além de algumas informações, ainda não divulgadas para a grande mídia, do trabalho que vem sendo realizado pela Prefeitura Municipal de São Paulo na área de coleta seletiva. Cópia impressa ou em CD Rom das palestras estão disponíveis na Secretaria da ABPol, uma vez que o tamanho dos arquivos não permitiria o download pela internet.

\section{Reologia e Processamento}

A primeira rodada coube à Comissão de Reologia e Processamento, com a apresentação de três palestras na parte da tarde do dia 3 de junho: - "Polímeros de alta performance" (Paulo A. dos Santos - GE Plastics), - "Problemas de injeção - causas e prováveis soluções" (Afonso Henriques Neto - Escola Senai Mário Amato) e - "Desafios em processamento e estrutura de polímeros para obtenção de propriedades diferenciadas" (Shinichi Tokumoto - Polibrasil Resinas).

A mesa-redonda, da qual participaram os palestrantes e convidados, teve como tema "Desenvolvimento de novos materiais e suas aplicações". Os integrantes da mesa teceram rápidas considerações sobre o tema, iniciando-se então os debates com o público presente.
O primeiro convidado enfatizou a importância das correlações existentes entre processamento, estrutura do material e as propriedades desejadas para um produto. $\mathrm{O}$ conhecimento dessas correlações é imprescindível para se talhar as propriedades de seu material de acordo com os requisitos necessários para um determinado produto, visando uma dada aplicação. Mencionou também que um dos palestrantes discorreu, entre outros tópicos, sobre como minimizar as linhas de solda. Na verdade, isso estaria camuflando o problema e entender as correlações entre o processamento e a estruturação na linha de solda vai definir se esse produto será bom ou não.

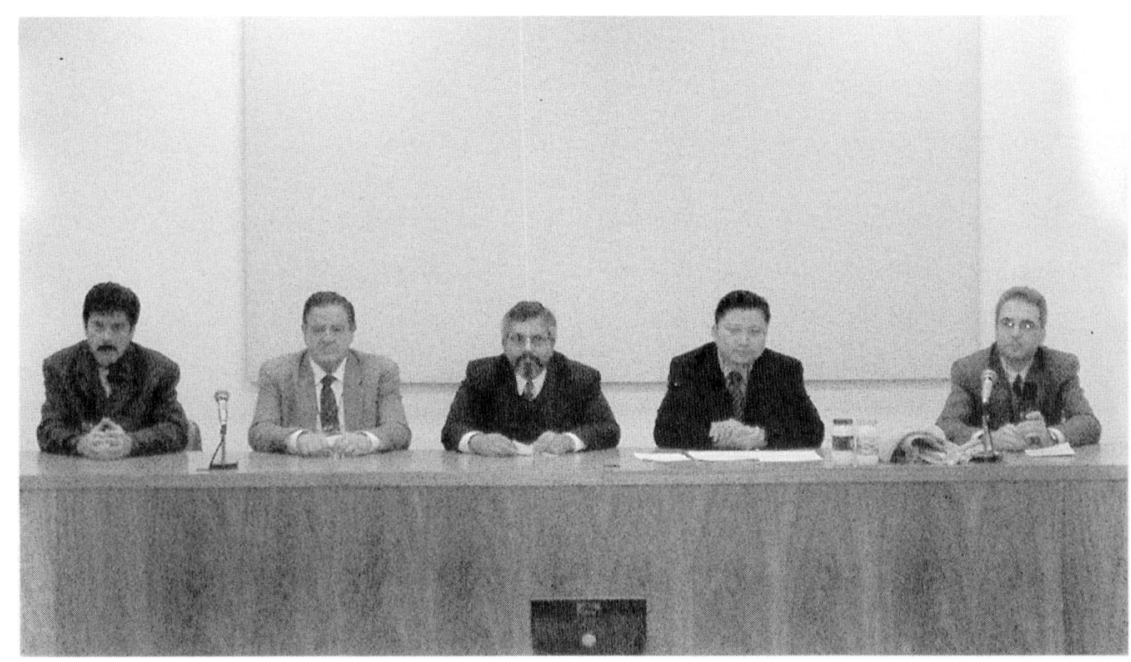

Uma outra colocação foi o alto custo de desenvolvimento de novos materiais com polimerização e a busca de novas opções com blendas mais cargas (reforço, fibra de vidro, carga mineral, etc), que proporcionam uma gama infinita de materiais, de possibilidades, tanto de custo como de performance.

Mencionou-se também a posição de uma empresa fabricante de negro de fumo e o trabalho que vem sendo feito, 
globalmente, no sentido de dar mais suporte ao usuário, questionando a aplicação e orientando, para melhor aproveitamento do produto.

Uma tendência das indústrias de tecnologia de ponta, como a eletroeletrônica, a telecom, a automobilística, é aplicar o conceito de engenharia reversa, como a melhor maneira de otimizar um produto: trabalhando em sua aplicação. Como o desenvolvimento de polímeros demanda muito tempo e investimento, através da inovação, da tecnologia e da criatividade, está-se procurando fazer compostos, fazer pequenas modificações para otimizar, sempre pensando na relação custo/benefício. Um exemplo é o polipropileno de altíssima fluidez. É a modificação de uma resina já existente, mas que passa a permitir ciclos bastante rápidos e com paredes bastante finas, tornando o material muito competitivo frente ao produto termoformado.

Indagado sobre o perfil do profissional que hoje atua numa empresa de vanguarda como a GE Plastics e sobre os desenvolvimentos que vêm de fora, o eng. Paulo dos Santos informou que a empresa, por ser multinacional e globalizada, definiu pólos de tecnologia, e um deles é a Índia. No Brasil a GE tem uma planta só de composição, não fazendo a polimerização. Hoje, há mais necessidade de se ser ágil na tradução do material do que em criar alguma coisa nova. Com a entrada da LNP no grupo, especializada em compostos e especialidades, com muita diversificação de cargas e modificadores, o produto é praticamente Taylor-made e a especificação que vem de fora já não serve tanto. O produto gerado passa, então, a ser específico para uma aplicação nacional. Quanto ao profissional, ele tem de ser cada vez mais eclético, fazer de tudo, ser ágil, ter iniciativa e usar muito mais inteligência emocional que racional. Indagado, ainda, sobre a relação custo $\mathrm{x}$ uso dos plásticos de engenharia em relação ao polipropileno, o representante da GE comentou que o plástico de engenharia deve ser encarado como um desbravador do mercado. Existe uma competição de mercado muito grande com o polipropileno, um plástico extremamente versátil. Uma empresa desenvolve um material, conquista um mercado, logo aparece outro produto e o primeiro é passado para trás, indo, então em busca de um novo nicho. Hoje se busca muito mais a substituição de materiais não-plásticos do que plásticos, como carcaças metálicas, peças de cerâmica ou de vidro, como no caso do farol de automóvel.

Um dos convidados destacou dois pontos fortes do polipropileno para a indústria automobilística - o preço e a densidade da resina, que possibilitam redução de custo e de peso. Foi lembrado, também, que a limitante, o divisor de água desses materiais, quando se fala de termoplásticos de engenharia e polipropileno, é a temperatura, que limita algumas aplicações.

Shinichi Tokumoto, que trabalha em uma empresa de polipropileno, comentou que há uma agressividade muito grande das indústrias do setor, tanto na aplicação quanto na modificação da resina. Ele acredita que há espaço para todos os tipos de polímeros e materiais, mas que esse espaço tem que ser explorado. Uma outra questão, também, é a função social que o negócio polímeros deve ter para o país, não visando apenas a rentabilidade das empresas. Se o país está buscando exportar, não seria o caso de as empresas entrarem também para o agrobusiness? O negócio dos polímeros pode ser impulsionado com a união de conhecimento de diversas áreas. Se o polipropileno ganhou novas aplicações nos últimos dez anos, foi uma conseqüência da coragem de quem conduz o negócio na região.

Fernando Cruz, coordenador de desenvolvimento de produtos da Rhodia Poliamida, reconheceu a indústria automobilística como propulsora do desenvolvimento do mercado de plástico, mas demonstrou preocupação com o elevado nível dos recursos necessários para pesquisa e desenvolvimento, que representam de 4 a $5 \%$ do faturamento. A empresa precisa investir para se manter competitiva, mas a indústria automobilística demanda redução de custos. Colocou então a seguinte questão: A pesquisa não pode ser desestimulada a médio e longo prazo, considerando-se que no Brasil as especificações sequer são definidas junto com as montadoras?

Outro participante lembrou que, embora a indústria automobilística seja a mais visível, existem desenvolvimentos muito grandes sendo realizados na área de eletroeletrônica, principalmente motivados por novas regulamentações e pela legislação do INMETRO para atender às normas de segurança. Uma outra indústria de porte, responsável por $40 \%$ do volume de plástico comercializado no Brasil e que vem sofrendo grande impulso por causa das novas tecnologias, é a indústria de embalagem. Ela tem alavancado muito o desenvolvimento do setor, embora a automobilística seja a mais visível e de mais glamour.

A Mesa-redonda foi encerrada com uma sugestão de maior agressividade no marketing tecnológico. As empresas que têm feito grandes investimentos em tecnologia, que estão conquistando mercado, devem chamar a indústria automobilística a participar de congressos e seminários, em especial as pessoas de marketing e de tecnologia, mesmo porque há deficiência de profissionais especializados na indústria automotiva. Outro aspecto levantado foi a necessidade de maior interação entre universidade e empresa, e a possibilidade de a $\mathrm{ABPol}$ ou a $\mathrm{ABNT}$ criarem uma norma única, dentro da linha do plástico, para uniformizar a questão da venda do material polimérico para a indústria automotiva. Começar uma normalização do setor, seja de tração, impacto ou tensão/deformação.

\section{Reciclagem}

As apresentações da segunda rodada começaram no período da manhã do dia 4 de junho, com palestras sobre Reciclagem de Plástico. Os temas abordados foram: - "Mercado Brasileiro de Reciclagem de Plásticos (Sílvia Rolim Plastivida); -"Incríveis Fontes de Recursos para Valorização, Reciclagem de Resíduos Sólidos e Meio-Ambiente"(Abílio Santos e Dulcy Arcuri - Scrap Integrated Recycling Co.); "Propriedades do compósito PP/Resíduo de Casca de Arroz 
(Siegfried H. Steudner - Volkswagen/EPUSP). A palestra "Coleta Seletiva Solidária da Prefeitura do Município de São Paulo", proferida por Rubens X. Martins, da Secretaria de Serviços e Obras da P.M. de São Paulo, é resumida nos parágrafos que seguem, adiantando, assim, informações de iniciativas do poder público que em futuro próximo estarão sendo divulgadas para a comunidade.

Iniciando sua apresentação do "Recicla São Paulo", o programa de coleta seletiva solidária em andamento na cidade de São Paulo, Rubens Martins apresentou rapidamente alguns dados que destacam as proporções de um programa implantado numa cidade com 10 milhões e 400 mil habitantes, como a geração de mais de 10 mil toneladas/dia de resíduos sólidos e um sistema de varrição de ruas de aproximadamente $6 \mathrm{mil} \mathrm{km} / \mathrm{dia}$. Mencionou os incineradores, já desativados, os aterros sanitários, os aterros inertes (destinados a restos de construção civil), as usinas de compostagem e os centros de triagem, foco principal da palestra.

O programa de coleta seletiva na cidade de São Paulo era bastante tímido até setembro de 2003, quando o novo programa foi montado, abrangendo hoje $50 \%$ da cidade. Estudos recentes sobre o perfil do lixo estão disponíveis na página da Prefeitura, demonstrando, por exemplo, uma queda significativa na destinação final dos resíduos a partir da aplicação da taxa de lixo. A partir de março de 2003, os 2,4 milhões de domicílios da cidade foram divididos em três terços: um não paga, outro paga um pouco e o terceiro terço começou a pagar. Combinando a cobrança da taxa de lixo e a coleta seletiva, os resíduos da usina de compostagem, que no início do ano eram de aproximadamente 600 mil toneladas/mês, chegaram a quase 2 milhões de toneladas/mês no final do ano.

A atual gestão, desde o início, começou um debate com movimentos organizados envolvidos com educação ambiental, coleta seletiva ou algum tipo de trabalho com catadores, mon- tando, então, o programa "Recicla São Paulo". Esse programa trabalha com três eixos principais - a gestão do entulho, a destinação final e a implantação de ecopontos, locais de entrega de materiais em pequenas quantidades - e o trabalho de base começou com a adequação da legislação, de forma que a Prefeitura pudesse firmar convênios com as cooperativas que surgiriam com a implantação do programa. Os objetivos são quatro: - o aumento da consciência ambiental, para melhorar a qualidade de vida e limpeza da cidade; - a preservação dos bens naturais, com a recuperação e reaproveitamento dos resíduos, como embalagens plásticas, vidros, etc; - o aumento da vida útil dos aterros sanitários; - a questão da inclusão social.

Quando montou o programa, a Prefeitura não optou pelo caminho mais fácil, que seria a contratação de uma empresa. Escolheu o caminho mais difícil e, a partir da articulação com movimentos organizados, trouxe para dentro do sistema público essas pessoas que estão na rua, fazendo a coleta e separando. Montou também toda a estrutura necessária, dotando os centros, com cerca de $1500 \mathrm{~m}^{2}$, de esteira, sacos de separação, equipamento de proteção individual, caminhões para coleta porta-a-porta e com braço mecânico para coleta dos contêineres de 2500 litros. Além disso, metade dos 5000 contêineres estão disponibilizados em condomínios, ruas, praças e poços de gasolina. Atualmente, com o funcionamento de 11 centros de triagem, 1 milhão e 100 mil domicílios são atendidos pela coleta seletiva porta-a-porta pelo menos uma vez por semana e 480 pessoas estão trabalhando dentro dos centros de triagem. Até dezembro de 2004 pretende-se chegar a 31 centros, ou seja, um centro para cada sub-prefeitura.

Além da montagem de toda a infra-estrutura necessária e da logística da coleta do material, a Prefeitura recorre a parcerias com universidades para executar todo um trabalho de formação permanente dos catadores, visando não apenas a separação do material, mas sua integração e sua sociabilidade, do ponto de vista da inclusão social. Os centros fazem a coleta, separação, prensagem, armazenamento e comercialização, cabendo à Prefeitura a indicação de compradores interessados, quando procurada. Para desenvolver um programa tão ambicioso, as parcerias são imprescindíveis, o que tem sido feito com a Federação do Comércio, Sindicato de Condomínios, o Centro Empresarial para Reciclagem, a Paulista Viva, Rádio Eldorado, parceiros na questão de divulgação e na educação ambiental.

Atualmente, a coleta seletiva está na faixa de 70 toneladas/dia, assim distribuídas: $57 \%$ - papel; $24 \%$ - plástico; $6 \%$ - vidro; $1 \%$ alumínio. Do plástico, $33 \%$ é plástico colorido, embora o PET seja o material que gera maior quantidade de recursos, com valor médio de comercialização de $\mathrm{R} \$ 800,00$ 
Total de material reciclável e valor da comercialização deplástico nas 11 centrais

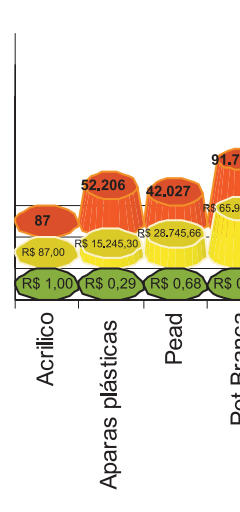

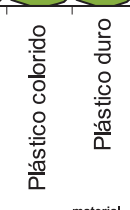

\begin{tabular}{|c|c|}
\hline & $\begin{array}{l}\frac{O}{0} \\
\frac{.0}{E} \\
\circ \\
\frac{0}{0} \\
\frac{.0}{0}\end{array}$ \\
\hline
\end{tabular}
Janeiro, Fevereiro e Março de 2004
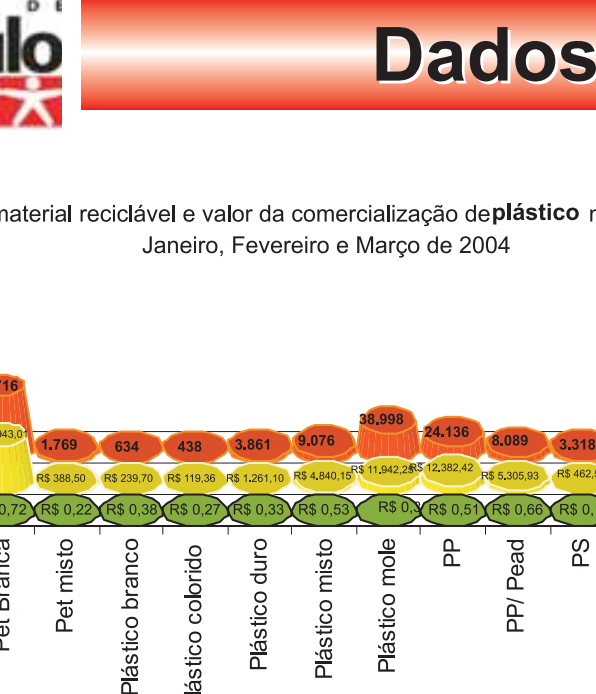

a tonelada. A média de retirada dos catadores é de aproximadamente $\mathrm{R} \$ 450,00$, em alguns casos chegando a $\mathrm{R} \$ 700,00$ e a $\mathrm{R} \$$ 800,00 .

Estima-se que 20 mil pessoas vivem nas ruas de São Paulo e de alguma forma coletam material. Por esses números pode-se ter uma idéia dos principais desafios do programa. Um deles é montar centros de triagem sem necessariamente desarticular as redes que existem, pois nem todos os catadores de rua devem querer ir para dentro de um centro. Outro desafio é coletar 700 toneladas diárias, ou seja, multiplicar por 10 o valor atual, e fazer com que a retirada média seja de $\mathrm{R} \$ 600,00$. Hoje se está trabalhando com 40 a 42 pessoas em média dentro do centro, num período de 8 horas. É possível trabalhar com 3 períodos de 8 horas e otimizar os recursos e a utilização das instalações. A instalação de um centro de triagem tem um custo de R\$430.000,00, acrescido de $\mathrm{R} \$ 28.000,00$ por mês com a locação dos caminhões para a coleta.

Outra preocupação tem a ver com a questão da descentralização do sistema de gestão, pois o centro de triagem deve estar integrado à sub-prefeitura onde está funcionando. Outro grande desafio é a consolidação do diálogo da sociedade civil com o poder público, para construir e manter a gestão compartilhada. Tem sido amplamente discutida a questão da remuneração dos catadores. Está em debate o que é mais vantajoso para as pessoas que estão dentro dos centros de triagem: serem remuneradas diretamente pelo poder público ou trabalharem com retiradas a partir do material comer-

\section{Sá̀ọaúlo PAP DAP}

cializado, como está sendo feito atualmente.

Encerrada a apresentação, iniciaram-se os debates da mesa-redonda sob o tema "Valorização da Reciclagem no Brasil". Inicialmente, foram levantados alguns pontos em relação à palestra anterior, como: a periodicidade da coleta seletiva porta-a-porta; - a ação de pequenas empresas que, à noite, retiram todo o material destinado à coleta dos centros de triagem, sem qualquer preocupação maior com as condições de trabalho dos catadores, muitas vezes crianças; - a possibilidade de os centros de triagem terem seu próprio desenvolvimento de transformação do produto, de forma a eliminar o intermediário.

Fernando J. Novaes, um dos membros da mesa discorreu sobre a reciclagem na indústria automobilística, uma reciclagem mais especializada, mencionando a desigualdade da relação das montadoras com o fornecedor de matéria-prima e o moldador e a exigência constante de redução de custos. Para a reciclagem ser viável, a ordem de grandeza de economia tem de estar entre 40 e $50 \%$ do custo do material virgem. Um outro aspecto muito importante para a conquista desse mercado é a qualidade e os critérios de uso. Os fabricantes de polímeros devem possuir uma gestão adequada, que possibilite uma confiabilidade e uma consistência do produto, baseadas em normas e especificações. Até 2015, 95\% do material de acabamento dos veículos tem que ser reaproveitado, tem que ser reciclado, então é necessário profissionalizar. Na Europa já

\section{Dados}

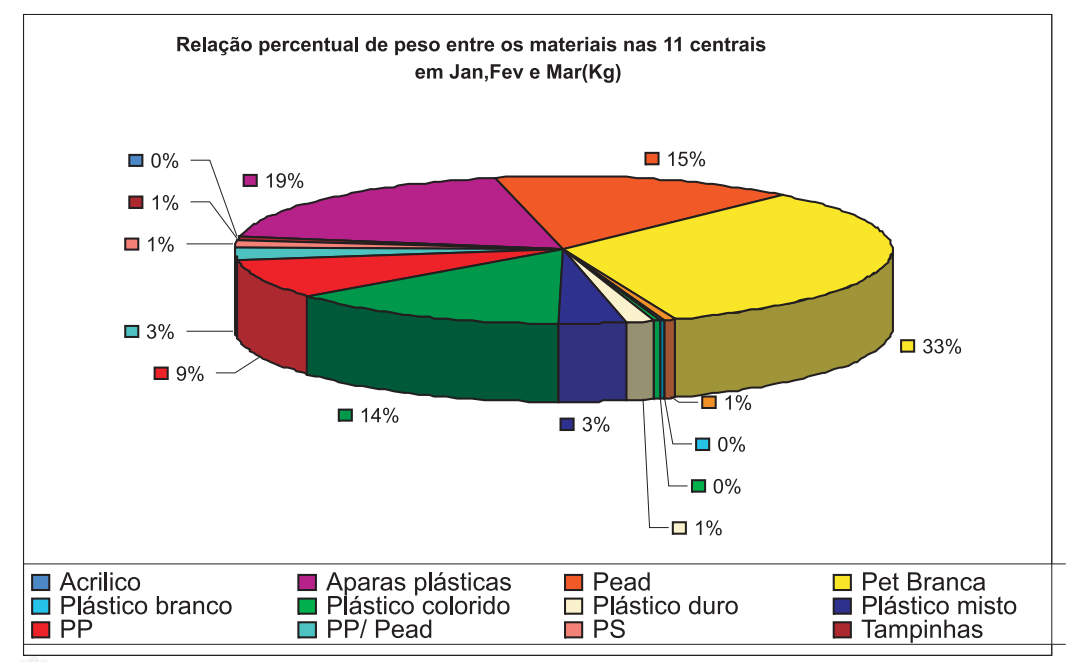


se tem a desmontagem seletiva para reutilização. Tudo o que se faz pensando no meio-ambiente é em função dos impactos que isso causa no meio, seja relativo a energia, despejo, emissões ou consumo de combustível, no que se refere à questão automotiva.

Em seguida, Rubens Xavier retomou a palavra, comentando a importância do programa de coleta seletiva, encurtando o caminho entre a coleta e o repasse do material para a indústria e também sobre a possibilidade de uma comercialização quase que direta com as empresas, ao aglutinar uma grande quantidade de material. A concentração de grandes quantidades de material causa um impacto considerável, tanto do ponto de vista de economia de energia como de preservação da natureza, além de contribuir para a inclusão social e cidadã, deixando as pessoas continuarem a fazer o que já faziam, só que de uma outra forma.

Outro ponto interessante, abordado por Siegfried Steudner, foi a parceria ecologia-economia. Questionar formas de reciclagem e reaproveitamento é muito mais uma questão de se pensar no nosso planeta, na nossa vida. A inércia de nosso sistema tem de ser quebrada, problemas imediatos como onde colocar o lixo, têm de ser resolvidos, porque o custo é cada vez maior. As cidades têm de tratar de forma adequada e econômica, não apenas o lixo, mas toda a questão ambiental.

Abílio Santos levantou algumas questões, comentando, inicialmente, a realização do primeiro leilão de resíduos do Brasil, a partir de julho, promovido pela Bolsa de Resíduos da FIESP. A iniciativa restringe a ação do intermediário e aumenta o valor do ganho, mas outras questões devem ser analisadas, como as normas adotadas: - o que é plástico? Como deve ser apresentado? Como deve ser embalado para a entrega? Ninguém viu a amostra, e geralmente ela é sempre melhor que o produto. Um outro problema seria o desenvolvimento de um produto desvinculado da preocupação de seu reaproveitamento ou biodegradabilidade. Finalizou sua exposição mencionando a deficiência do banco de dados existente no Brasil quando se trata de meio-ambiente, que apresenta números muito diferentes, o que faz uma grande diferença ao se pleitear um financiamento.

Outros pontos foram também levantados pelos presentes, como a necessidade de profissionalização dos catadores, tanto a nível técnico como de gestão; a necessidade de pesquisas para tornar cada vez mais limpo o material pós-industrial; o diálogo entre recicladores e montadoras; o papel limitante do licenciamento na eliminação de intermediários, etc.

\section{Caracterização}

A terceira etapa do Seminário apresentou temas relacionados à Identificação e Caracterização de Polímeros. Os palestrantes abordaram os seguintes tópicos: - "Interpretando Curvas de DSC"(Luci B. Machado - IPEN); "Caracterização por FT-IR de Materiais Utilizados na Indústria Aeroespacial" (Rita C. L. Dutra - CTA); - 'Proprie- dades Dinâmico-Mecânicas de Blendas de Reator de PP/EPR/ PE"(Márcia Pires - Braskem); - "A Evolução dos Interlaboratoriais"(Selma Jaconis - IPT).

A temática da mesa-redonda foi a discussão da "Importância dos Interlaboratoriais para o Sistema da Qualidade das Empresas" e alguns pontos foram destacados. Houve unanimidade entre os integrantes da mesa da importância da confiabilidade dos laboratórios, cuja falta pode acarretar prejuízos incomensuráveis de imagem, como, por exemplo, um cliente perder mercado ao atrasar o lançamento de um produto; a empresa aceitar uma devolução de material (com todo ônus financeiro que isso acarreta) simplesmente por causa de um problema de erro analítico. Um caso verídico, ocorrido recentemente, foi o de uma empresa de hot melt que ficou parada, aguardando um resultado de DSC. Mais grave ainda é quando resultados incorretos podem comprometer decisões importantes, especialmente quando se desenvolve um produto global.

A outra face da questão, porém, são os benefícios. A empresa que participa dos programas interlaboratoriais ganha credibilidade nas auditorias e na certificação, de acordo com depoimento de participantes da mesa, representando Braskem e Rhodia Poliamida, por exemplo. Os resultados individuais de cada empresa são analisados dentro de uma média de grupo. Não existem valores absolutos, mas relativos. Uma empresa pode ter um erro sistemático se o valor da propriedade que ela avalia está sistematicamente abaixo ou acima da média do grupo. Não importam os resultados em si. O que vale é que um determinado laboratório esteja dentro da média do grupo, porque isso irá refletir como todos estão fazendo. Quem se desvia do padrão é que pode estar com problema, e aí também é muito importante a atuação da ABPol. Nos relatórios dos programas interlaboratoriais ninguém sofre constrangimento, porque cada empresa tem seu código de participação e, quer os resultados sejam altamente positivos ou negativos, o nome da empresa nunca vem a público. Um outro dado muito importante, e para isso exige-se que o coordenador do interlaboratorial seja conhecedor do ensaio, são as orientações oferecidas, visando identificar os problemas e sugerir ações corretivas. Não se pode nunca perder a visão

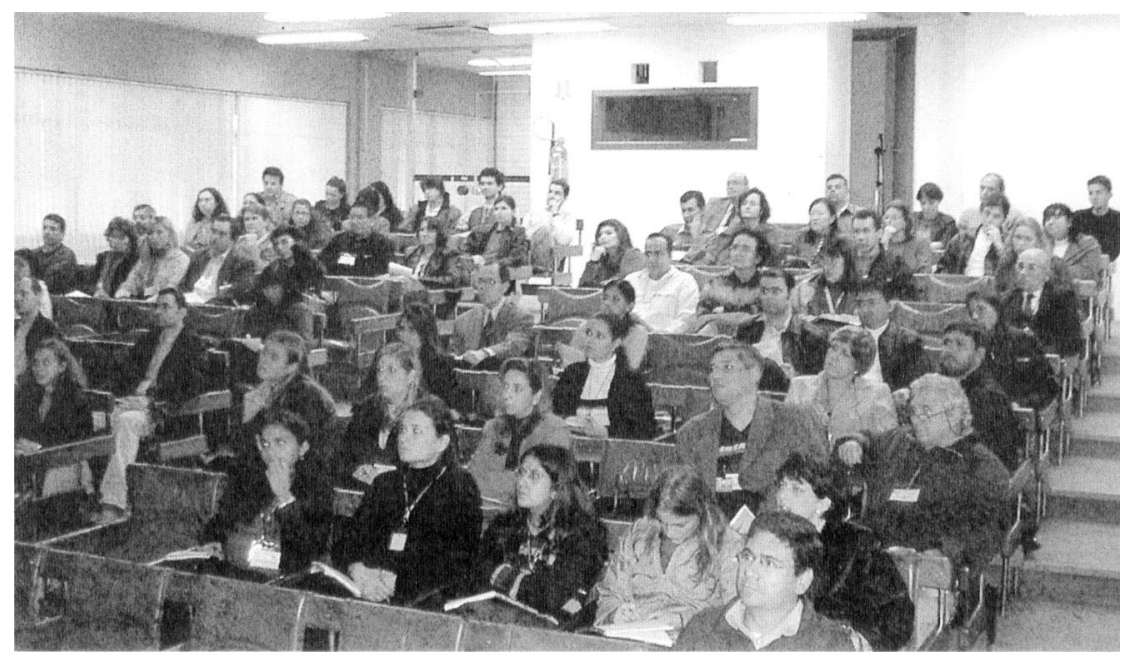


de quais são as variáveis do processo que influem no resultado da medição e o programa interlaboratorial é ainda mais importante, na medida em que alerta o laboratório para a necessária checagem dessas variáveis durante a realização do teste. Nem sempre o problema é do equipamento, mas que pode ser, por exemplo, do operador, nem sempre consciente da importância do rigor com que deve operar.

Uma consideração interessante foi colocada por um representante do INMETRO. A Norma 17025 representa para o credenciamento de laboratórios o mesmo que a ISO 9000 para a certificação das empresas e um dos requisitos básicos para o credenciamento, tanto dos laboratórios de calibração quanto os de ensaios, é que haja comparações laboratoriais em estágio de proficiência. Apesar de ter um setor que faz esses ensaios, o objetivo principal do INMETRO é divulgar essa cultura metrológica, que passa pelos ensaios de proficiência e pelos ensaios interlaboratoriais. O representante desse Instituto deixou o convite para que ABPol e IPT se integrem gratuitamente à lista existente na página do INMETRO de todos os provedores de ensaios de proficiência em comparações laboratoriais, de forma que essa informação possa estar disponível até mesmo quando as pessoas acessarem o site de fora do Brasil.

Encerrando este resumo, ficam os agradecimentos da Diretoria da ABPol àquelas empresas que mais uma vez contribuíram para o patrocínio do $8^{\circ}$ Seminário das Comissões Técnicas: Charis Technologies, Dp Union Instrum. Analítica e Científica Ltda, Emic Equipamentos e Sistemas de Ensaio Ltda., Imp. e Exp. de Medidores Polimate Ltda, Innova S/A, Plastivida, Polibrasil Resinas S/A. Apoio: Dinateste, IPT

Notícia elaborada por Fátima S. Cordebello, secretária executiva da ABPol 